\title{
ADVANCED DIGITAL LEARNING ENVIRONMENTS ON EDUCATIONAL INSTITUTIONS - AN EXPERIMENT
}

Dalila Duraes, Paulo Novais, Algoritmi Center, University of Minho, Portugal

\section{Abstract}

It is unquestionable to say that we live in a hyper-connected world, where technology is present in all spheres of our life. Furthermore, it is the backbone for the transformation of our society, which is continually changing and requires continuous adaptation of the human being to the environment. (Durães, Carneiro, Bajo, \& Novais, 2016). In this paper, we present experience during the Pandemic situation with students at high school. The idea is to improve learning and motivated students to participate in the demands of the task by the teachers.

Keywords: Digital Learning Environment, Digital Skills, Methodologies approach, Online Learning.

\section{Introduction}

The coronavirus pandemic has changed education forever because schools, universities, teachers, and students had to adapt to distance learning. There are considerable differences between online learning and face-to-face learning. The first requires that students in online learning be more responsible and disciplined since they have more freedom to search for content. The second requires a great familiarity of users with the use of computers. Finally, the third distinguishes the traditional interaction between teacher, student, and content becomes more complicated with the introduction of technology. In this way, teachers, students, content, and technology had to improve in recent times, to better adapt to the new reality lived.

In a traditional learning environment, the student and the teacher are the key elements in the classroom. Together, the teacher and student take a set of physical, social, emotional, mental characteristics of the classroom. Technologies influence the way the teacher relates to the student and, consequently, affect the way the learning process will progress (Durães, Cardoso, Bajo, \& Novais, 2017). Teacher-student relationships are a crucial aspect of learning success and are one of the main aspects that help determine the success or failure of the teacher's work. Relationships considered positive, concerning respect and empathy, 
Duraes, D., \& Novais, $P$.

Advanced Digital Learning Environments on Educational Institutions - An Experiment

emphasize all students' skills and motivate them throughout the learning process (Hamre \& Pianta, 2006). Hence, in this new phase, this topic has become a focal point.

For these reasons, the school should have tools that can engage students and capture their attention. Advances in computers and wireless technologies have also influenced the educational environment, generating a new approach to Ambient Intelligent Systems. The rapid development of technologies, combined with access to content in a wide variety of environments, allows students to experience new learning situations beyond the walls of the school (Durães, Carneiro, Bajo, \& Novais, 2016).

Another aspect to consider is the level of attention of the students since it directly affects student outcomes. Attention is a cognitive process, which is strongly linked to learning (Pimenta et al., 2015). When it comes to acquiring new knowledge, attention can be considered one of the most critical mechanisms (Mancas, Ferrera, Ritche, \& Taylor, 2016), where the student's level of attention affects learning outcomes, and lack of attention can define a student's success. However, for various reasons, students may not be predisposed to learning. Besides, each student has a particular way of acquiring knowledge, that is, their learning style. In this sense, in online environments, the teacher must have instruments that point out potential distractions that may indicate a lack of predisposition to learning (Durães, Cardoso, Bajo, \& Novais, 2017).

Nowadays, students deal with constant notifications in the e-mail, social media, messaging apps, advertisements and so on (see Figure 1). They live immersed in beeps, vibrations, notifications, and icons that blink and that continuously attract the attention of students distracting them (Gottlieb, 2012). Even if they immediately return to the lesson task, the fact that they had to consciously assess the stimuli to decide whether or not they were significant at the time made brain resources waste (Davenport \& Beck, 2013; Simola, Hyönä, \& Kuisma, 2015). So, it's important that students still motivated and engaged for leaning.

In this paper, we present experience during the Pandemic situation with students at high school of Caldas das Taipas, Guimarães. The idea is to improve learning and motivated students. This paper is organized as follow: Section 2 presents the State of the Art.; Section 3 presents the Methodology applied in the experiment; Section 4 presents Results and Discussion; and finally, Section 5 presents the Conclusions. 


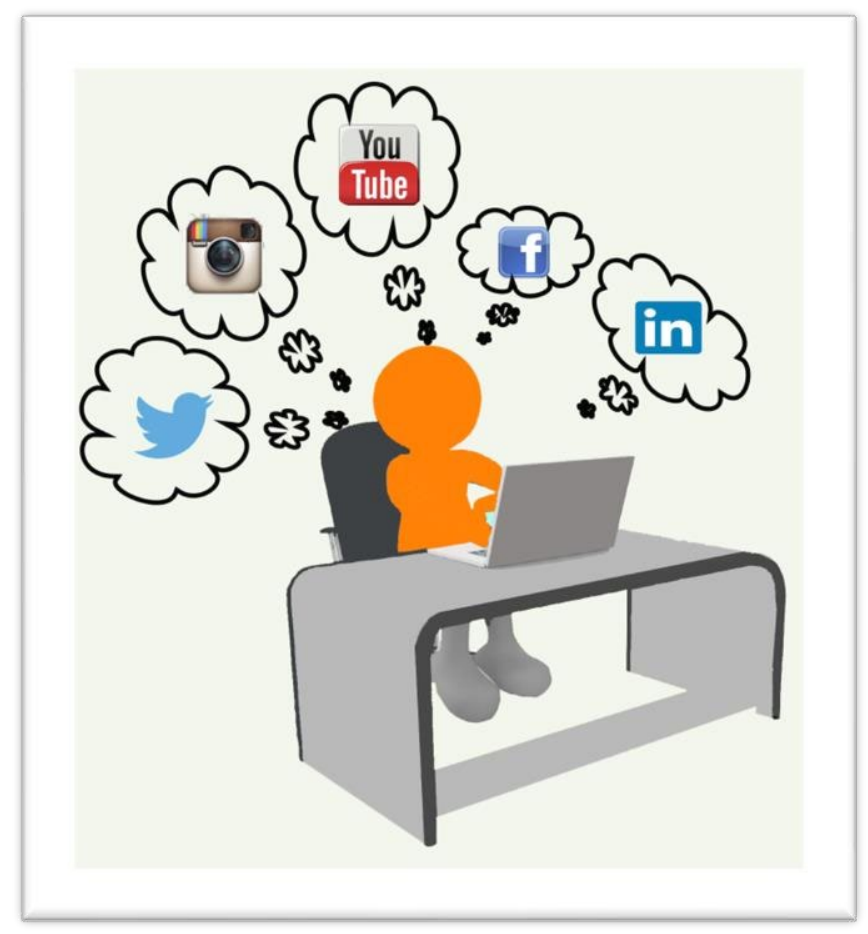

Figure 1. Students deal with constant notifications

\section{State of Art}

Based on Figure 2, which present a visual representation of the completed student dimension framework that shows that the four dimensional interact with each other. We can say that exist four dimensions: Knowledge, skills, character, and meta-learning (Holmes, Bialik, \& Fadel, 2019).

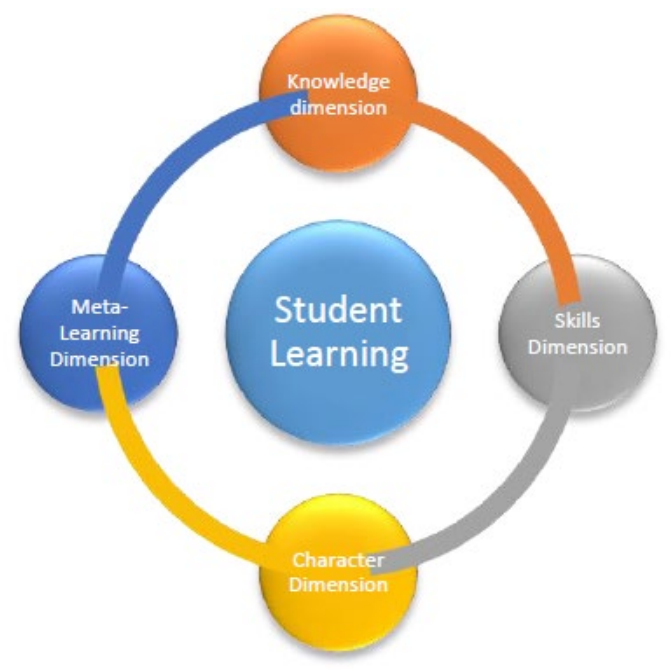

Figure 2. Student learning dimension

The Knowledge dimensional describe what the student knows and understand. The skills dimension rationalizes what the student can do with what he knows. Character dimensions justify how the student behave and engage in the world. Finally, Meta learning dimension explain how the student reflect and adapt to new situations (Holmes, Bialik, \& 
Duraes, D., \& Novais, $P$.

Advanced Digital Learning Environments on Educational Institutions - An Experiment

Fadel, 2019). Based on this student dimension we can design interactions between knowledge areas and skills, character qualities, and meta-learning strategies (Fadel, Trieling, \& Bialik, 2016). Examples are expounded in Table 1.

Table 1: $\quad$ Example of construction of interaction between dimensions.

\begin{tabular}{|c|c|c|c|c|c|c|}
\hline \multirow{2}{*}{$\begin{array}{l}\text { Modern } \\
\text { Knowledge }\end{array}$} & \multicolumn{2}{|c|}{ Skills } & \multicolumn{2}{|c|}{ Character } & \multicolumn{2}{|c|}{ Meta-learning } \\
\hline & Creativity & $\begin{array}{l}\text { Critical } \\
\text { Thinking }\end{array}$ & Mindfulness & Curiosity & Growth & Metacognition \\
\hline $\begin{array}{l}\text { Entrepreneurship } \\
\text { Wellness }\end{array}$ & & & & & & \\
\hline
\end{tabular}

\section{Attention}

Attention means focusing on clear thinking, among one of several subjects or objects that may capture mind simultaneously. Attention implies the concentration of mental powers upon an object by closing or careful observing or listening, which is the ability or power to mentally concentrate (Mancas, 2007; 2015). In that sense, the concept of attention may be also defined as the transforming of a huge acquired unstructured data set into a smaller structured one where the main information is preserved (Mancas, Ferrera, Ritche, \& Taylor, 2016). According to the authors Mancas, Ferrera, Ritche, and Taylor (2016) attention is the first action of perception that analyses the outer real world and turns it into an inner conscious representation and it is also the gate to conscious awareness.

\section{Methodologies Approach}

There are several methodologies that teacher can apply in online or face-to-face learning, namely Project Based Learning, Problem Based Learning, Challenge Based Learning, Gamification, Gamification Based Learning, Team Based Learning, and Flipped.

Project and Problem Based Learning are teaching methodologies that promote the learning process based on real or realistic questions/problems that require the active participation of students in the construction of solutions/products (Mills \& Treagust, 2003).

Challenge Based Learning it is a teaching methodology that promotes the learning process based on challenges. It starts with a great idea and develops with an essential question, a challenge, guiding questions, activities, resources, determining and articulating the solution, taking measures to implement the solution with the public, and evaluating the results (Johnson, Smith, Smythe, \& Varon, 2009).

Gamification uses elements characteristic of games in non-game situations, and Gamification Based Learning uses games in learning (Al-Azawi, Al-Faliti, \& Al-Blushi, 2016). 
Duraes, D., \& Novais, $P$.

Advanced Digital Learning Environments on Educational Institutions - An Experiment

Team Based Learning it is a strategy for promoting collaborative learning with strategically formed teams. It implies the students' prior preparation, based on available materials, individual and team evaluations through discussion with peers, followed by a discussion with the teacher (Michaelsen, Knight, \& Fink, 2004).

Flipped it is a teaching and learning methodology that reverses the traditional logic of approaching themes in the classroom / formal context. Students previously explore the content made available by the teacher before class and during the class discuss these contents/themes (Tucker, 2012).

\section{Methodology}

From the framework of the developed environment described in Figure 3 it is possible conclude that we had created a set of web-resources, then we have worked with the students applying some methodologies, and finally we had used several technologies. The approach followed in this article is based on weekly online activities during the confinement period. It was applying between $17^{\text {th }}$ March 2020 and $15^{\text {th }}$ July 2020.

At the beginning of each week, the document was made available with the objectives that the students would have to reach that same week. In the same way, the requirements that the students had to present and the respective deadlines were presented.

During the week, students asked questions using available technologies. When the students did not ask questions, the teachers sent a contact email to check if the work was being carried out. Before the end of the week, students had to submit their work on the platform.

At the end of each week, an online session was held, where each student made their presentations. Subsequently, the other students could also make suggestions that could later be re-submitted. 

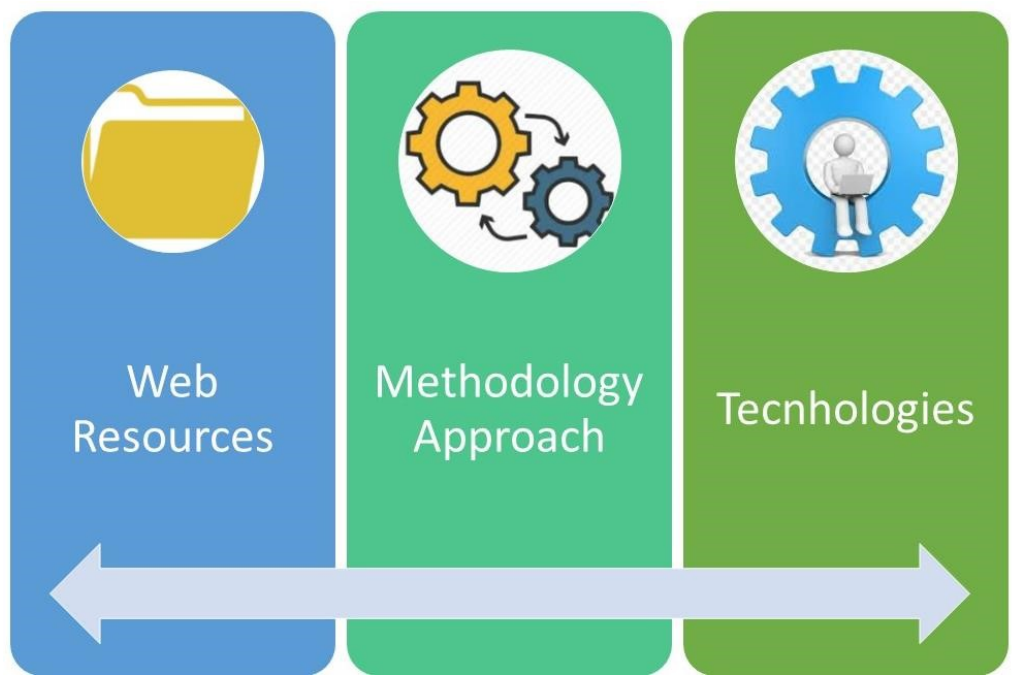

Figure 3. Framework applied

The methodologies used in asynchronous session was Challenge Based Learning methodology. In synchronous sessions was applied Flipped Classroom methodology.

The tools used were: (a) platform, google classroom; (b) technologies, email, google chat, adobe master suite collection; and (c) online session platform, zoom us.

In the case of this work, one of the fundamental requirements is that the students' routines, during the performance of this monitoring, are not disturbed by the data collection process, as any disturbance can have negative consequences on the result.

\section{Population}

The study was carried out at Caldas das Taipas High School, where each student has a computer connected at the Internet. All student used the google classroom platform to receive the tasks for each week and submitted their work. All on-line synchrony session was two hours.

The students attended the $12^{\text {th }}$ year and were students of the professional multimedia course. In total the class had 23 students, of which 13 were female and 10 males. There were 2 teachers, one male and one female. When the student had a question or asked for an opinion, he did it for both teachers simultaneously. The two teachers were obliged to answer, even if they gave the same opinion.

\section{Results and Discussion}

The total of on-line sessions was 17. Figure 4(a) it is presented the number of students that assisted to synchronism session in each session. The average of participation in each session was 20 students. 


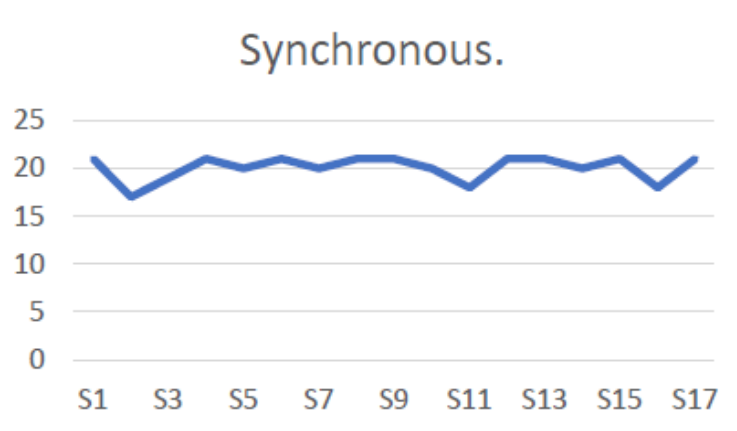

(a)

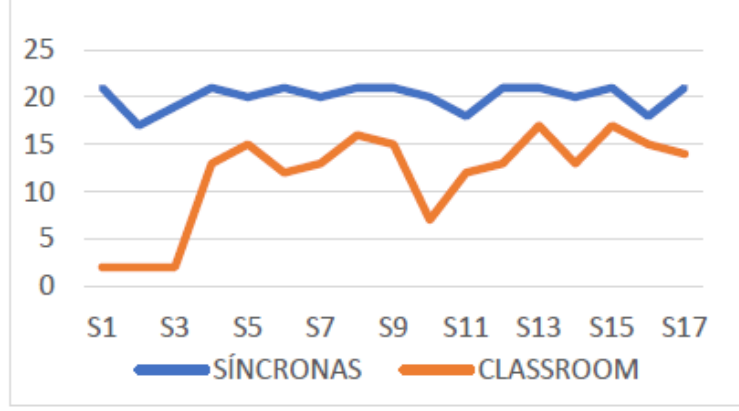

(b)

Figure 4. (a) Number of Students per session in synchronous session. (b) Comparison of synchronous session and classroom submission per student.

In Figure 4(b) we presented a comparison between the participations synchronous session and the classroom submission platform.

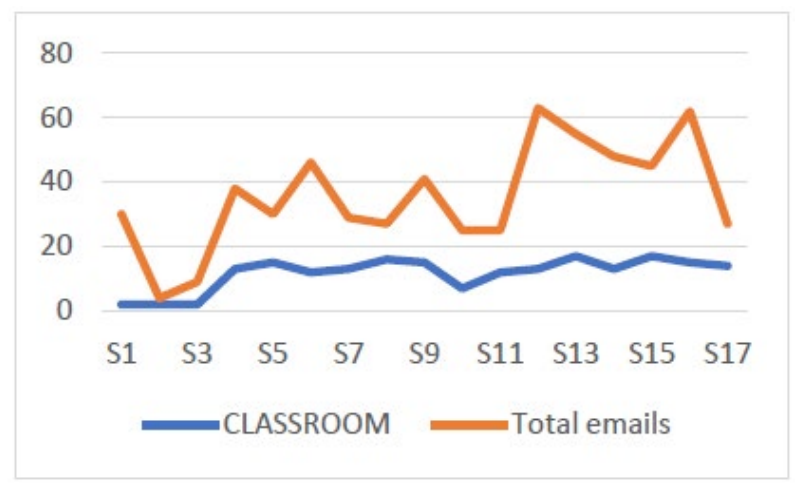

Figure 5. Comparison between activity of Classroom and the number of emails with teachers.

Figure 5 presented a comparison between classroom platform and emails. In each session several emails were exchanged with the teachers. Besides, the same student exchanged a high number of emails per session. The average of emails exchanged with teachers by session was 35.53, and each student exchange email per session in average 8.35.

All students were assessed by a mixed jury of 4 persons. The jury was composed by the two teachers, an invited teacher from other school in the same area, and a person from a multimedia company. All students obtained good results and all students transited the discipline.

\section{Conclusions}

In this paper, we presented the methodology applied to one classroom in pandemic confinement. It was applied between $17^{\text {th }}$ March 2020 and $15^{\text {th }}$ July 2020 . Because it was a subject of work-related training it was created a set of web-resources for each week. Then we have worked with the students applying Challenge Based Learning methodology for the asynchronous session, and Flipped Classrooms for the synchronous session. 
Duraes, D., \& Novais, $P$.

Advanced Digital Learning Environments on Educational Institutions - An Experiment

The technologies used were Google Classroom, email, Google Chat, Adobe Master Suite collection; and Zoom Us.

Finally, the students were obtained good results and all students transited the discipline.

In future work we intended to implemented more technologies, namely assessment by peer review.

\section{References}

Al-Azawi, R., Al-Faliti, F., \& Al-Blushi, M. (2016). Educational gamification vs. game based learning: Comparative study. International Journal of Innovation, Management and Technology, 7(4), 132-136.

Davenport, T., \& Beck, J. (2013). The attention economy: Understanding the new currency of business. Harvard Business Press.

Durães, D., Cardoso, C., Bajo, J., \& Novais, P. (2017). Learning Frequent Behaviors Patterns in Intelligent Environments for Attentiveness Level. In F. Prieta, Z. Vale, L. Antunes, T. Pinto, T. Campbell, J. Vicente, \& M. Moreno (Eds.), International Conference on Practical Applications of Agents and Multi-Agent Systems, PAAMS 2017: Trends in Cyber-Physical Multi-Agent Systems. The PAAMS Collection $-15^{\text {th }}$ International Conference (pp. 139-147). Springer.

Durães, D., Carneiro, D., Bajo, J., \& Novais, P. (2016). Supervising and Improving Attentiveness in Human-Computer Interaction. In P. Novais, \& S. Konomi (Eds.), Intelligent Environments (vol. 21, pp. 255-264). IOS Press Ebooks.

Fadel, C., Trieling, B., \& Bialik, M. (2016). Four-Dimensional Education: the Competencies Learners. Boston: Center for Curricula Redesign.

Gottlieb, J. (2012). Attention, learning, and the value of information. Neurocomputing $76(2), 281-295$.

Hamre, B., \& Pianta, R. (2006). Student-Teacher Relationships. Association of School Psychologists National.

Holmes, W., Bialik, M., \& Fadel, C. (2019). Artificial intelligence in education. Boston: Center for Curriculum Redesign.

Johnson, L. F., Smith, R. S., Smythe, J. T., \& Varon, R. K. (2009). Challenge-based learning: An approach for our time. The New Media Consortium, 1-38.

Mancas, M. (2007). Computational Attention - Toward Attentive Computers. Press Universitaire de Louvain. 
Mancas, M. (2015, December 31). Attention in computer science - Part 1. News and insights from EAI community [Blog post]. Retrieved from http://blog.eai.eu/attention-in-computer-science-part-1/

Mancas, M. (2015, November 26). Attention in computer science - Part 2. News and insights from EAI community [Blog post]. Retrieved December 31, 2016, from http://blog.eai.eu/attention-in-computer-science-part-2/

Mancas, M., Ferrera, V., Ritche, N., \& Taylor, J. (2016). Why Do Computers Need Attention? In M. Mancas, V. P. Ferrera, N. Ritche, \& J. G. Taylor (Eds.), From Human Attention to Computational Attention: A Multidisciplinary Approach (pp. 1-6). New Yoork: Springer Science+Business Media LLC.

Michaelsen, L. K., Knight, A. B., \& Fink, L. D. (2004). Team-based learning: A transformative use of small groups in college teaching.

Mills, J. E., \& Treagust, D. F. (2003). Engineering education - Is problem-based or project-based learning the answer. Australasian Journal of Engineering Education, 3(2), 2-16.

Pimenta, A., Gonçalves, S., Carneiro, D., Riverola, F., Neves, J., \& Novais, P. (2015). Mental workload management as a tool in e-learning scenarios. Proceedings of the International Conference on Pervasive and Embedded Computing and Communication Systems (PECCS), 25-32.

Simola, J., Hyönä, J., \& Kuisma, J. (2015). Perception of visual advertising in different media: from attention to distraction, persuasion, preference and memory. Frontiers Media SA.

Tucker, B. (2012). The flipped classroom. Education Next, 12(1), 82-83. 